\title{
On the Relationship between Language and Culture
}

\author{
Kristine Harutyunyan \\ Yerevan State University
}

\begin{abstract}
$\mathrm{T}$ he exact nature of the relationship between language and culture has fascinated, and continues to fascinate people with a wide variety of backgrounds. That there should be some kind of relationship between the sounds, words and syntax of a language and the ways in which speakers of that language experience the world and behave in it seems so obvious, as, in fact, a truism. It would appear that the only problem is to decide the nature of the relationship and to find suitable ways of demonstrating it.

The fact that no society exists without culture reflects the need for culture to fulfill certain biological and psychological needs in human beings. Consider the bewildering host of confusing and contradictory facts and propositions and ideas that present themselves every day to any human being; some organization of these facts is necessary to provide some order to potential chaos, and therefore conceptual networks of reality evolve within a group of people for such organization. The mental constructs that enable us thus to survive are a way of life that we call "culture".

Culture, therefore, is the "know-how" that a person must possess to get through the task of daily living; only for a few does it require knowledge of some, or much music, literature, and the arts.

The word culture can be taken in the sense in which it is used by cultural anthropologists, according to whom culture is something that everybody has, in contrast with the "culture" which is found only in "cultured" circles - in opera houses, universities and the like. The term is used differently by different anthropologists, but always refers to some characteristics shared by a community, especially those which might distinguish it from other communities. Some anthropologists are interested in what is called "material culture"- the artifacts of the community, such as pottery, vehicles or clothing.

Language is the principal means whereby we conduct our social life. When it is used in contexts of communication, it is bound up with culture in multiple and complex ways. The members of a community not only express their experience but also create it through language. Thus, language expresses and also embodies cultural reality.

Language is a system of signs that is seen as having itself a cultural value. Speakers view their language as a symbol of their social identity. The prohibition of its use is often perceived by its speakers as a rejection of their social group and their culture. We can say that language symbolizes cultural reality (Kramsch 1998:3).

The language of a particular society is an integral part of its culture, and the lexical distinctions drawn by each language will tend to reflect the culturally important features of objects, institutions and activities in the society in which the language operates.

A language is a treasure-house, repository of culture. Language is a transmitter, a carrier of culture, it passes on the treasures of national culture that are preserved in it, from generation to generation. Language is an instrument of culture. It forms the identity of a
\end{abstract}


native speaker by forcing upon him the world-view, mentality, attitude to people inherent in it. Language is a mirror of culture, it creates a language picture of the world.

Language and culture are undoubtedly connected. Sapir believes that language is an immensely ancient heritage of the human race. Language is an essentially perfect means of expression and communication among every known people. Of all aspects of culture, it is a fair guess, language was the first to receive a highly developed form and its essential perfection is a prerequisite to development of culture as a whole (Sapir 1949:349).

We use the term "culture" to refer to all the ideas and assumptions about the nature of things and people that we learn when we become members of social groups. Culture can be defined as "socially acquired knowledge". We develop awareness of our knowledge, and hence of our culture, only after having developed language. The particular language we learn through the process of cultural transmission provides us, at least initially, with a ready made system of categorizing the world around us and our experience of it.

Culture establishes for each person a context of cognitive and affective behavior, a blueprint for personal and social existence. Perception involves the filtering of information even before it is stored in memory, resulting in a selective form of consciousness. What appears to you to be an accurate and objective perception of a person, a custom, an idea, is sometimes "jaded" or "stilted" in the view of someone from another culture. Misunderstanding is therefore likely to occur between members of different cultures. It is apparent that, as an ingrained set of behaviors and modes of perception, culture becomes highly important in the process of learning a second language. Language is part of culture and culture is part of language; the two are intricately interwoven so that one cannot separate the two without losing the significance of either language or culture. The acquisition of a second language, except for specialized, instrumental acquisition, is also the acquisition of a second culture.

Culture may be defined as the kind of knowledge which we learn from other people, either by direct instruction or by watching their behaviour. Since we learn our culture from those around us, we may assume that we share it with them, in particular, when we use language. The same will be true for any knowledge that we share with other people, regardless of whether we learned it from them or not; for example, even if we are born aware of certain things, such as vertically and the basic lay-out of people's faces, such shared knowledge is equally important for language. The term "thought" covers a number of different types of mental activity, and lies in the province of cognitive psychology. We shall distinguish first between memory and inference, and then between concepts and propositions, as objects of memory or inference.

What is the relation between thought and culture? Given the definition of culture as "socially acquired knowledge", it is easy to see that culture is one part of memory, namely the part which is "acquired socially", in contrast with that which does not involve other people. This distinction is anything but clear, so we must not put too much weight on it, but it might distinguish between propositions which are known to be true from one's own experience and those which have been learned from other people. An example of the first kind would be "I had sausages for lunch today", which is excluded from the notion "culture", whereas a proposition like "Columbus discovered America" clearly belongs to cul- 
ture, as something one has learned from other people. Similarly, some concepts are cultural and some are not. A non-cultural concept, on the other hand, is one which we build without reference to other people, as a convenient way of interpreting our experience "me", or "the way my wife talks", or "the smell of paint".

To what extent can distinction be made between cultural and non-cultural knowledge? If it means an approximation to the concepts or propositions in other people's minds, it is cultural. One of the most interesting things about cultural knowledge is the extent to which people can interpret each other's behaviour and arrive at more or less the same concepts or propositions. For instance, every year millions of people attend different concerts in Britain, but with very few exceptions they appear to share the same concepts for categorizing concepts (pop, classical, jazz and so on), and the same propositions about what constitutes appropriate behaviour. If people did not share such detailed knowledge, their behaviour in concerts could not be as predictable as it in fact is, especially since the conventions are somewhat arbitrary.

On the other hand, it does not follow that non-cultural knowledge must differ from person to person, since different people can arrive at similar conclusions on the basis of similar experiences of the universe or similar genetic predispositions. For instance, if we find that all human beings have a concept of "vertical dimension", there is no need to assume that they have all learned it from other people in order to establish a chain of connections between them; it is much more likely because they all live in a world dominated by gravity and full of human beings who walk upright; or even that it is inborn and needs no learning. (Wierzbicka 1992: 534)

Thus we find that there are three kinds of knowledge:

1) cultural knowledge, which is learned from other people;

2) shared non-cultural knowledge, which is shared by people within the same community or the world over, but is not learned from each other;

3) non-shared non-cultural knowledge, which is unique to the individual.

We should also pay attention to the two issues which have dominated the study of language in relation to culture and thought. Firstly, to what extent do cultures differ from one another? Are they all in some sense cut to the same mould, reflecting a common underlying 'humanity', or do they differ arbitrarily and unrestrictedly from one another, reflecting the fact that different people live in very different intellectual and physical words worlds? This is the question of RELATIVITY and DETERMINISM.

One aspect of relativity is very easily demonstrated since we can point to items in some languages which certainly express meanings not expressed in others. This can be seen in the difficulties of translating between languages that are associated with different cultures, and consequently have names for different ranges of customs (birthday-party), objects (hovercraft, sausage), institutions (university) and so on. A moment's thought will show how large a proportion of everyday vocabulary is tied to culture-specific concepts - concepts which simply do not exist in other cultures. This is especially true if concepts get their content from all the propositions that mention them, because then the details will become much more important. For example, the English words brown, monkey, chair, jug and carpet are all more or less untranslatable into French, in the sense that 
no single French word expresses precisely the same concept as the corresponding English word; different words must be chosen on different occasions even though it is apparently the same concept that is expressed in each case by the English word (Lyons 1981:67). The same can be said for Armenian words like e.g. qupultun, huphuu, huu々pun.

Different languages do not simply provide different ways of expressing the same ideas, but they are also different in the more fundamental sense that the ideas that can be expressed differ from language to language. We can call this kind of variability SEMANTIC RELATIVITY. English has a word for 'carpet', but French does not, and so on. One possibility is that all the concepts that serve as word-meaning in different languages are simply different ways of combining a limited range of rather basic "components". For example, the English verb eat is translated into German in two different ways, according to whether the eater is a human (essen) or an animal (fessen). Clearly both of these German verbs have more specific meaning than eat, but the concepts "human" and "animal" exist in English as well, so the difference between the two languages lies simply in how the concepts "human", "animal" and "eat" are combined into word-meaning. If all the differences can be explained in this way, relativity will actually be very limited indeed. This possibility leads to a search for universal components of meaning in terms of which all meanings can be expressed. It lay behind the "componential analysis" which used to be described in introduction to semantics, according to which concepts like "man" could be decomposed into the components "male", "human" and "adult". It has also stimulated some interesting attempts to develop a universal semantic vocabulary for defining all words in all languages. However, as soon as this kind of analysis is applied to concepts like "carpet" it becomes apparent that at least the immediate "components" of culture-specific concepts must themselves be further culture-specific concepts. The goal of a small universal vocabulary still looks very remote.

The world is determined by many factors peculiar to a particular nation: these may be history, geography, mode of life, mentality and so on. Any explanation of the connection between linguistic pattern and the rest of culture cannot be abstracted from its ethnographic, social basis. And even though we have talked about cultural universals, the natural environments in which different societies live, not to mention their institutions and patterns of behaviours, are so diverse, that it is extremely doubtful whether one can talk profitably about the semantic structure as an imposition of form upon an underlying (perceptual, physical or conceptual) substance common to all languages.

Each particular language provides names for the thoughts which we want to express. Understanding the meaning of the words requires partly social and partly individual cognition. It is obvious that each person possesses his own individual stereotypes, tastes, superstitions, etc. The same is true for society where different people live.

When one is inclined to study the determining influences of language on cognitive processes, he/she must distinguish between two different but related approaches. One approach grows essentially out of work in the psychological tradition, the other - out of an anthropological tradition; these are the fields we have come to call respectively psycholinguistics and ethnolinguistics. The former most characteristically deals with the generic function of language in shaping cognitive processes, while the latter is typically 
concerned with the comparative problem of how structural differences among languages, in both their lexical and grammatical aspects, systematically relate to differences in the cognitive or other behavior of their speakers. The two approaches are complementary. In fact, the latter presupposes the former, but they approach the problem at different levels, using different kinds of linguistic data.

The semantic mapping of the universe by a language is, in general, arbitrary, and the semantic "map" of each language is different from those of all other languages.

\section{References:}

1. Kramsch, C. (1998) Language and Culture. Oxford: Oxford University Press.

2. Lyons, J. (1981) Introduction to Theoretical Linguistics. Cambridge: Cambridge University Press.

3. Sapir, E. (1949) Selected Writings of Edward Sapir in Language, Culture and Personality. USA: University of California Press.

4. Yule, G. (1998) Pragmatics. Oxford: Oxford University Press.

5. Wierzbicka, A. (1992) Semantics, Culture, and Cognition. Oxford: Oxford University Press.

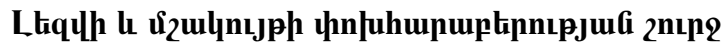

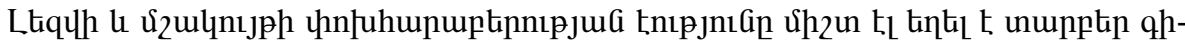

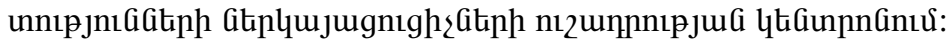

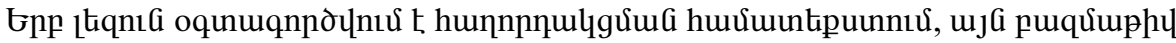

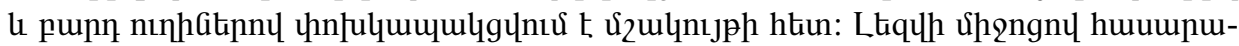

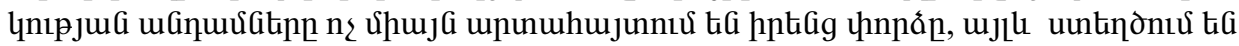

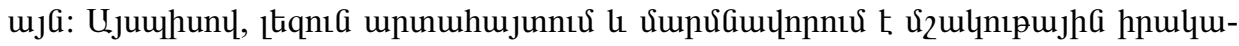
GnıpjnıG:

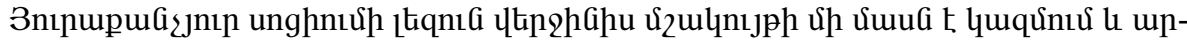

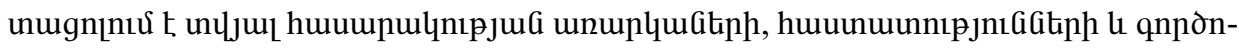

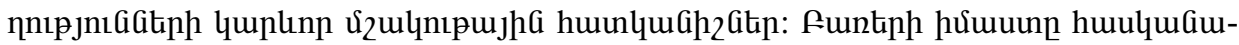

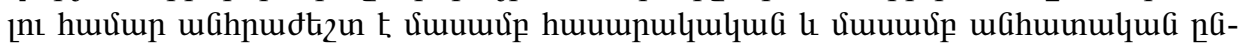

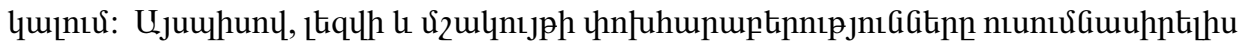

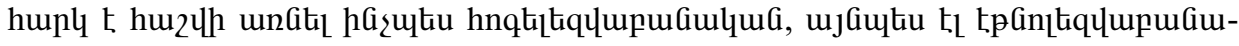
quai ununtignưfitinn: 